\title{
CROSSTALK BETWEEN THE MICROBIOME AND CANCER CELLS BY QUORUM SENSING PEPTIDES
}

Evelien Wynendaele ${ }^{\mathrm{a}}$, Frederick Verbeke ${ }^{\mathrm{a}}$, Matthias D’Hondt ${ }^{\mathrm{a}}$, An Hendrix ${ }^{\mathrm{b}}$, Christophe Van De Wiele $^{\mathrm{c}}$, Christian Burvenich ${ }^{\mathrm{d}}$, Kathelijne Peremans $^{\mathrm{e}}$, Olivier De Wever ${ }^{\mathrm{b}}$, Marc Bracke $^{\mathrm{b}}$ and Bart De Spiegeleer ${ }^{\mathrm{a}, *}$

${ }^{a}$ Drug Quality and Registration (DruQuaR) group, Faculty of Pharmaceutical Sciences; Ghent University; Ottergemsesteenweg 460, Ghent, B-9000; Belgium.

${ }^{b}$ Department of Radiation Oncology and Experimental Cancer Research, Faculty of Medicine and Health Sciences; Ghent University Hospital; De Pintelaan 185, Ghent, B-9000; Belgium.

${ }^{c}$ Department of Radiology and Nuclear Medicine, Faculty of Medicine and Health Sciences; Ghent University Hospital; De Pintelaan 185, Ghent, B-9000; Belgium.

${ }^{\mathrm{d}}$ Comparative Physiology and Biometrics, Faculty of Veterinary Medicine; Ghent University; Salisburylaan 133, Merelbeke, B-9820; Belgium.

${ }^{\mathrm{e}}$ Department of Medical Imaging, Medicine and Clinical Biology of Small Animals, Faculty of Veterinary Medicine; Ghent University; Salisburylaan 133, Merelbeke, B-9820; Belgium.

*Address correspondence to Bart De Spiegeleer, Bart.DeSpiegeleer@UGent.be, Tel: +329264 8101

(Our reference: 2014-096n) 


\title{
Highlights
}

- Some quorum sensing peptides promote colon cancer cell invasion and angiogenesis.

- Quorum sensing peptide Phr0662 influences tumor progression by EGFR targeting.

- Cytokine profiles confirm the peptide's stimulatory effect on metastasis in vitro.

- The microbiome-mammals crosstalk may explain the microbiome's effect on health.

\begin{abstract}
To date, the precise role of the human microbiome in health and disease states remains largely undefined. Complex and selective crosstalk systems between the microbiome and mammalian cells are also not yet reported. Research up till now mainly focused on bacterial synthesis of virulence factors, reactive oxygen/nitrogen species (ROS/RNS) and hydrogen sulphide, as well as on the activation of exogenous mutagen precursors by intestinal bacteria. We discovered that certain quorum sensing peptides, produced by bacteria, interact with mammalian cells, in casu cancer cells: Phr0662 (Bacillus sp.), EntF-metabolite (Enterococcus faecium) and EDF-derived (Escherichia coli) peptides initiate HCT-8/E11 colon cancer cell invasion, with Phr0662 also promoting angiogenesis. Our findings thus indicate that the human microbiome, through their quorum sensing peptides, may be one of the factors responsible for cancer metastasis.
\end{abstract}

\section{Keywords:}

Quorum sensing peptides; colon cancer; metastasis; microbiome; angiogenesis 


\section{INTRODUCTION}

Studies of the human microbiome revealed an individual and age-related diversity of microbes, occupying different habitats like skin, mouth, mammary gland, vagina and gut [1-5]. The beneficial effects of the gastrointestinal microbiota are currently being exploited in daily life by the use of probiotics. These products, most often positioned as functional foods, claim to restore the gut microbiota composition, possibly preventing gut inflammation or other intestinal or systemic disease phenotypes [6]. The most commonly studied organisms for probiotic therapies in the treatment of gastrointestinal diseases include organisms of the genera Bacillus, Enterococcus, Escherichia, Faecalibacterium and Propionibacterium. Enterococcus faecium, together with Bacillus subtilis and Lactobacillus spp., were investigated as probiotics for acute gastroenteritis, while Streptococcus spp., B. subtilis and E. coli were explored for their use as probiotics in irritable bowel syndrome; a reduced duration or decreased abdominal pain of both gastrointestinal diseases was established. Manipulation of the microbiota with rationally selected pre- or probiotics can inhibit pathogens, strengthen epithelial barrier functions and supply the host with key nutrients (e.g. vitamins) [7]. Despite these claimed health benefits, it has also to be cautioned that certain safety aspects should be taken into account when using probiotics: taxonomic identification of the probiotic strain is necessary to avoid pathogenicity, as well as inhibiting the risk of infection and antimicrobial resistance [8]. The use of probiotics is indeed already associated with diverse side effects, e.g. bacteremia, fungemia and gastrointestinal ischemia; critically ill patients and immune-compromised individuals are the most-at-risk populations [9].

However, the interactions with the host can affect metabolic, neurological, inflammatory and immunological functions as well, and also the development of cancer can directly or indirectly be promoted [10]. For example, the progress of colorectal cancer can directly be initiated by DNA- 
damaging superoxide radicals or genotoxins, both produced by gut (mucosa-associated) bacteria. Indirectly, bacteria can induce cell proliferation or pro-carcinogenic pathways by T-helper cells or Toll-like receptors, respectively [11]. Human microbiome studies have revealed significant differences between cancer patients and healthy controls regarding the relative abundance of certain microbes. In colon cancer patients, an increased population of e.g. Escherichia coli was observed in feces, inducing colitis and colibactin synthesis and thereby promoting inflammation and cancer [12].

Although the quorum sensing process within gram-positive bacterial colonies is already extensively described in literature, the direct link between quorum sensing peptides and tumor development remains unexplored. Recent investigations revealed that the quorum sensing process is activated in the human gut: a set of acylhomoserine lactone (AHL) molecules, i.e. signaling molecules produced by gram-negative bacteria, were identified in human feces of gastrointestinal disease patients as well as healthy subjects [13]. Moreover, bacterial quorum sensing molecules are likely to play a role in bacterial colonization of mucosa, thus requiring quorum sensingmediated biofilm formation [14]. Finally, Casula and Cutting showed the germination of Bacillus subtilis spores in the murine gastrointestinal tract, thereby probably requiring signaling peptides for quorum sensing pathway activation [15]. Although thus not yet investigated, it is very likely that also quorum sensing peptides are found in the human intestinal tract.

In this study, we utilize a collagen invasion assay, transcriptome assay, Chick Chorioallantoic Membrane (CAM) assay, cytokine profiling and phospho-receptor tyrosine kinase array to investigate the influence of quorum sensing peptides on mammalian cancer cells. Our preliminary observations unexpectedly reveal that quorum sensing peptides stimulate metastasis behavior of human colon cancer cells, thereby opening new perspectives on the role and applications of the 
microbiome on the guest's health, with the possibility of translating these findings into other biological and applied medical fields as well.

\section{MATERIALS AND METHODS}

\subsection{Cell culture}

An epithelial subclone from human ileocecal colorectal adenocarcinoma cells (ATCC ${ }^{\circledR}$ CCL224), i.e. HCT-8/E11, was grown in high-glucose Dulbecco's Modified Eagle's Medium (DMEM), supplemented with 10\% (V/V) fetal bovine serum (FBS), 1\% (w/V) L-glutamine, 100 $\mathrm{U} / \mathrm{ml}$ penicillin and $100 \mu \mathrm{g} / \mathrm{ml}$ streptomycin (all from Invitrogen/GIBCO, Gent, Belgium) in a humidified atmosphere of $5 \% \mathrm{CO}_{2}$.

\subsection{Collagen type I invasion assay}

Morphology changes of HCT-8/E11 cells were investigated using previously described methods [16]. In brief, 10000 cells were seeded per well in a 48-well plate, containing $150 \mu 1$ of collagen type I gel per well, thereby investigating cell morphology 24 hours post-treatment (Leica DMI3000B phase contrast microscope). Peptide solutions (Supplementary Table 1, all from GL Biochem, Shanghai, China) were prepared using ultrapure water (with or without DMSO), obtaining final peptide concentrations of $1 \mu \mathrm{M}, 100 \mathrm{nM}$ and $10 \mathrm{nM}$ after 1:10 dilution using growth medium; the placebo sample solely contained ultrapure water. Two independent morphology 'scorings' were obtained for each of the 3 replicates; peptides were found positive if collagen-invasion or cell-stretching at minimum 2 consecutive concentrations was established at minimum 2 out of the 3 replicates. 


\subsection{Human Transcriptome Array}

Peptide (EDF-analogue: $10 \mathrm{nM}$, Phr0662 and EntF-metabolite: $100 \mathrm{nM}$ and $1 \mu \mathrm{M}$ ) treated cells were analyzed in duplicate (independent treatment and analysis) for whole transcriptome expression using Affymetrix GeneChip Human Transcriptome Array 2.0. by AROS Applied Biotechnology A/S (Aarhus, Denmark); RNA expression was compared with placebo (ultrapure water) treated samples. Data analysis was performed using Transcriptome Analysis Console (Affymetrix) and MetaCore (Thompson Reuters) software programs.

\subsection{Chick Chorioallantoic Membrane (CAM) assay}

The Chick Chorioallantoic Membrane (CAM) assay was performed as described by Sys et al:: 6 days after (pre-treated, $100 \mathrm{nM}$ ) tumor cell transfer to the fertilized eggs, CAM was microscopically scored and histologically examinated after H\&E staining [17,18]. For quantification of microscopically observed neovascularisation, an average CAM score was calculated: the number of blood vessels in the $1 \mathrm{~mm}$ diameter ring around the $2 \mathrm{~mm}$ radius tumor centre was determined. Significant differences were evaluated using the Mann-Whitney U test.

\subsection{Cytokine profiling}

Cytokine expression was investigated using the Human XL Cytokine Array kit (R\&D Systems, Abingdon, United Kingdom), following the instructions of the supplier. In brief, cell supernatant was obtained after 24 hours of incubation with Phr0662 (100 nM) and 102 different cytokines analyzed in duplo using spotted capture antibodies, followed by incubation with detection antibodies and chemiluminescent visualization. Membranes are finally exposed to X-ray films for 1-10 minutes. The mean (blank corrected, $\mathrm{n}=2$ ) pixel density is calculated using ImageJ 
software and compared with placebo treatment. Significant differences were evaluated using the independent samples t-test.

\subsection{Phospho-receptor tyrosine-kinase array}

A human phospho-receptor tyrosine kinase (RTK) array kit (R\&D Systems, Abingdon, United Kingdom) was used to detect phosphorylation levels of 49 different RTK after Phr0662 treatment (100 nM) of HCT-8/E11 cells, following the manufacturer's instructions. Cell lysates were prepared after 5 minutes of peptide incubation and incubated with capture antibodies (in duplo). Previous experience with the receptor tyrosine kinase assay showed that a 5 minutes exposure time is a generally acceptable exposure time to obtain a sufficient degree of receptor activation/phosphorylation without dropping down to basal phosphorylation levels due to phosphatase activity. Incubation was followed by treatment with detection antibodies and Horseradish Peroxidase for chemiluminsescent visualization. X-ray films were again analyzed for mean (blank corrected, $\mathrm{n}=2$ ) pixel density and compared with placebo results using the ImageJ software program. Significant differences were evaluated using the independent samples t-test.

\section{RESULTS}

\subsection{Epithelial to mesenchymal (EMT)-like transition and related cell migration activities}

To investigate the potential role of chemically diverse quorum sensing peptides in oncology [19, Wynendaele et al., unpublished results), we explored their morphologic effect on a human epithelial colon cancer cell line, i.e. HCT-8/E11. Three quorum sensing peptides, or metabolites thereof, were found to significantly induce tumor cell invasion through a collagen type I extracellular matrix: Phr0662 (ERNNT, 98.24\%), an EntF-metabolite (SNLVECVFSLFKKCN, 80.63\%) and an EDF-analogue (NWN, 98.40\%) (Figure 1), while others, e.g. cAM373 
(AIFILAS, 97.82\%) and iAD1 (LFVVTLVG, 97.74\%) [20], both originating from Enterococcus faecalis, do not induce invasive characteristics. This epithelial to mesenchymal (EMT)-like process (i.e. observation of invasive cellular extensions) is one of the main mechanisms involved in colorectal cancer metastasis, establishing metastatic disseminations with potential lifethreatening consequences [21].

Peptide Phr0662 is synthesized by Bacillus species [22]. The quorum sensing peptide designated Extracellular Death Factor (EDF), originally described by Kolodkin-Gal et al., is responsible for the mazEF and chpBIK-mediated cell death in Escherichia coli. This intestinal commensal bacterium synthesizes this EDF peptide during logarithmic growth stages when stress-situations are induced $[23,24]$. Our study now enlarges the role of EDF to mammalian cells. EntF is synthesized by Enterococcus faecium, a commensal bacterium in healthy humans and animals, which is responsible for a number of nosocomial infections [25]. Enterococcus faecium, together with Enterococcus faecalis, is the primary source of reactive oxygen species (ROS), causing genomic alterations which are correlated to colorectal cancer [26]. However, based on the results of this study, its quorum sensing peptide (or its metabolite) can contribute to metastatic tumor behavior as well.

The microscopically observed invasive characteristics were further corroborated by whole transcriptome analyses on both placebo and peptide-treated tumor cells (Table 1). RNA extraction was performed on a heterogenous mixture (i.e. cells with and without induced invasive cellular extensions) instead of on isolated HCT-8/E11 cells, and only two duplicates were performed in this exploratory study, so the standard (parametric) ANOVA p-values are only given for the sake of completeness but are not meant to conclude any statistical significance (requiring more data and non-parametric evaluation). This exploratory study was meant to observe trends based on the mean fold-change. The up- or downregulation of certain genes 
supported the phenotypic observations of cellular invasiveness: e.g. the upregulation of histone cluster 1 H4 (HIST1H4A-F/H-L) and CXorf61 (Cancer/Testis Antigen 83 (CT83) or Kita-Kyushu Lung Cancer Antigen $(K K L C 1))$ is associated with cell cytoskeleton remodelling. Histone H4 is involved in different biological pathways through its link with $\beta$-arrestin 1, activin A and Notch1. Via $\beta$-arrestin 1 , Histone $\mathrm{H} 4$ is linked to cell migration and metastasis in colon cancer in vivo [27]. The Histone H4-activin A link is again associated with cell migration and cytoskeleton remodeling (via Smad3) and cell proliferation (via Smad4) in colon cancer [28,29]; in normal human epithelial cells, activin A can induce EMT as well. Finally, via the link with Notch1, in colon cancer, it causes metastasis and cell invasion; a deregulation of the Notch signaling pathway thus affects EMT and tumor aggressiveness [30,31]. Through its link with micro-RNA 520h (miR-520h), CXorf61 upregulation is associated with increased tumor cell mobility and enhanced in vitro cell invasion activity [32]. Moreover, downregulation of micro-RNA 558 ( $m i R$ 558 ) is associated with a bad prognosis of colon cancer outcome, indicating tumor metastases and thus EMT-like behaviour [33]. Micro-RNA 644a (miR-644a) functions by directly binding to its target site in the 3' untranslated region of glyceraldehyde-3-phosphate dehydrogenase (GAPDH) and $\beta$-actin, thereby significantly repressing their expression [34]. Downregulation of $m i R-664 a$ thus upregulates $\beta$-actin levels, leading to increased cell motility and cell migration [31].

\subsection{Angiogenesis confirms metastatic potential of quorum sensing peptides}

Downregulation of microRNA 222 (miR-222), as observed 24 hours after Phr0662 and EDFanalogue peptide addition, is associated with tumor growth reduction (through PUMA) and apoptosis induction [35], next to a bad cancer prognosis [33]. MicroRNA 222 is also highly expressed in endothelial cells, possessing anti-angiogenic properties through its targets c-kit 
(mast/stem cell growth factor receptor kit, CD117), p27Kip1, p57Kip2 (cyclin-dependent kinase inhibitor 1C) and cyclin G1 [36]. The downregulation after quorum sensing peptide addition thus initiates angiogenesis. This angiogenic effect was analyzed for Phr0662, seen the highly changed transcriptomic profile of the cancer cells after 24 hours of treatment. Our Chick Chorioallantoic Membrane (CAM) assay results confirmed these pro-angiogenic properties (Figures $2 \mathrm{a}$ and $2 \mathrm{~b}$ ): its addition clearly promoted neovascularisation, thereby facilitating metastasis of the tumor. Without tumor cells, the addition of the peptide alone did not promote neovascularisation, confirming the crosstalk between the peptide and the cancer cells (i.e. indirect angiogenic effect) (Figure 2c). Histological evaluation of the membrane confirmed the invasive tumor cell properties through the chorion into the mesoderm, induced by the quorum sensing peptide (Figure 2d).

Cytokine screening after Phr0662 treatment of the cancer cells revealed pro-angiogenic effects as well (Figure 3): the quantitative increase of the vascular endothelial growth factor (VEGF), hepatocyte growth factor (HGF), interleukin 6 (IL-6) and stromal cell-derived factor 1 (SDF-1 $\alpha$ or CXCL12) all indicated an induction of angiogenesis by the investigated peptide [37]. IL-6 was also found to drive tumor initiation and subsequent growth and metastasis, with a poor clinical outcome observed in colorectal cancer patients. Through its link with STAT3, it promotes the expression of VEGF and FGF, supporting the rapid vascularization required for tumor growth and metastasis $[38,39]$.

\subsection{Phr0662 targets the epidermal growth factor receptors EGFR and ErbB2}

Receptor Tyrosine Kinase (RTK) screening of Phr0662-treated HCT-8/E11 cells revealed a 2 times higher ErbB2 (HER2/neu) and a significant increase in epidermal growth factor receptor 
(EGFR, HER1 or ErbB1) phosphorylation compared to the placebo cell samples (Figure 4). A comparable activity is observed for the Phr0662 quorum sensing peptide and the autocrine ligand TGF- $\alpha, 5$ minutes after HCT-8/E11 treatment.

The EGFR is overexpressed in many types of cancers, especially colorectal cancer, and is significantly associated with tumor-node-metastasis and a more aggressive clinical tumor progression [40]. This regulation of cellular functions is achieved by activating different intracellular signaling cascades: phosphatidylinositol 3-kinase (PI3K/Akt), the ras/raf/MEK/mitogen-activated protein kinase (MAPK) and the signal transducer and activator of transcription (STAT) pathways. EGFR signaling regulates the synthesis and secretion of different angiogenic growth factors as well, including VEGF; overexpression of ErbB2 also leads to increased angiogenesis [41].

\section{DISCUSSION}

Despite our small quorum sensing peptide set, our results suggest that some quorum sensing peptides can exert (part of) their effects through the epidermal growth factor receptor (EGFR), thereby activating the Ras/raf/MEK/MAPK, PI3K/Akt and STAT intracellular signaling cascades [41], leading to an altered gene transcription and finally tumor metastasis (Figure 5). $\beta$-arrestin 1, which is linked to HIST1H4 and thus possibly upregulated after peptide treatment, can activate the EGFR pathway as well, thereby playing a pivotal role in colon cancer metastasis [27]. Other mechanistic plausible hypotheses, such as the possibility of quorum sensing peptide activation of G-protein coupled receptors (GPCR), followed by an induced EGFR phosphorylation (i.e. EGFR transactivation) [42], however still need to be investigated. Next, Smad proteins (i.e. Smad 2, 3 and 4) can be stimulated through Activin A binding with its ActRII receptor, linking both cell 
cytoskeleton remodeling and cell migration to quorum sensing peptide presence $[28,43]$. The upregulation of HIST1H4 can be associated with increased Notch1 stimulation, again connected to cancer metastasis, together with angiogenesis and $\mathrm{NF}-\kappa \mathrm{B}$ production $[30,44]$; $\mathrm{NF}-\kappa \mathrm{B}$ in turn contributes to the progression of colorectal cancer by regulating cell proliferation, angiogenesis and tumor metastasis [45]. Micro-RNA's block mRNA translation and thus impede the synthesis of specific proteins by recruiting the micro-RNA-induced silencing complex (miRISC) to target mRNAs [46]; downregulation of micro-RNA 222 and 644a thus increases KIT and $\beta$-actin protein expression, respectively, thereby promoting endothelial cell proliferation and migration (angiogenesis) [36,47] and tumor cell invasiveness and motility [34]. $\beta$-actin can be upregulated through the IL-6 receptor pathway as well: the increased IL-6 expression after quorum sensing peptide treatment, as observed with our cytokine array, activates $\beta$-actin phosphorylation, again promoting tumor cell migration [48]. Both the transcriptome outcomes and cytokine results thus correspond well and are visually confirmed by the collagen invasion and CAM assays. A good correlation is observed for VEGF as well: an increased IL-6 pathway activation leads to VEGF upregulation [49], which is again observed in our cytokine array; VEGF can then trigger the VEGF receptor (VEGFR) pathway in endothelial cells, leading to altered gene transcription and subsequently angiogenesis. The pro-angiogenic cytokines SDF-1 $\alpha$ and HGF both activate the Ras/raf/MEK/MAPK, PI3K/Akt and STAT intracellular signaling cascades through CXCR4 and MET receptor binding, respectively. These cytokine-receptor axes are involved in tumor progression, angiogenesis and metastasis [50,51]. Future investigations concerning the identification of quorum sensing peptide targets, should however be performed to confirm our initial findings and to have more mechanistic insights on the effect of these and other quorum sensing peptides on colon cancer cells. 
These exploratory in vitro results thus indicate metastasis-promoting characteristics for some quorum sensing peptides. Assuming the in vivo presence of these molecules influenced by the individual microbiota composition, our findings may potentially have a great impact on the patient's health, with effects on cancer metastasis. Exploiting our findings, it would be interesting to consider how we can prevent these pro-metastatic effects? First, it may be important to adjust the patient's life style, including diet and hygiene measures. The influence of food pattern cannot be neglected, e.g. switching from a low-fat, plant (non- or limited digestible) polysaccharide-rich diet to a high-fat, high-sugar diet can shift the structure of the gut microbiota within a single day [52,53]. Appropriate hygiene measures will diminish the risk of unwanted infections.

\section{ACKNOWLEDGEMENTS}

We thank G. Wagemans and M. De Meulemeester for technical support and assistance with the CAM assays and H\&E staining. This work was supported by the Special Research Fund of Ghent University [Grant number BOF 01J22510 to B.D.S. and E.W.] and the Institute for the Promotion of Innovation through Science and Technology in Flanders (IWT-Vlaanderen) [Grant numbers 131356 to F.V. and 101529 to M.D.]. The microarray data are deposited at AROS Applied Biotechnology under project numbers A2224 and A2080.

\section{REFERENCES}

1. Arthur JC, Perez-Chanona E, Mühlbauer M, Tomkovich S, Uronis JM, Fan T-J, et al. Intestinal Inflammation Targets Cancer-Inducing Activity of the Microbiota. Science 2012;338:120-3.

2. Schwabe RF, Wang TC. Bacteria Deliver a Genotoxic Hit. Science 2012;338:52-3. 
3. Garagnani P, Pirazzini C, Franceschi C. Colorectal Cancer Microenvironment: Among Nutrition, Gut Microbiota, Inflammation and Epigenetics. Curr Pharm Des 2013;19:765-78.

4. The Human Microbiome Project Consortium. Structure, function and diversity of the healthy human microbiome. Nature 2012;486:207-14.

5. Claesson MJ, Jeffery IB, Conde S, Power SE, O’Connor EM, Cusack S, et al. Gut microbiota composition correlates with diet and health in the elderly. Nature 2012;488:178-84.

6. Hemarajata P, Versalovic J. Effects of probiotics on gut Microbiota: mechanisms of intestinal immunomodulation and neuromodulation. Therap Adv Gastroenterol 2013;6:3951.

7. Preidis GA, Versalovic J. Targeting the Human Microbiome With Antibiotics, Probiotics, and Prebiotics: Gastroenterology Enters the Metagenomics Era. Gastroenterology 2009; 136:2015-31.

8. Ishibashi N, Yamazaki S. Probiotics and safety. Am J Clin Nutr 2001;73:465s-70s.

9. Didari T, Solki S, Mozaffari S, Nikfar S, Abdollahi M. A systematic review of the safety of probiotics. Expert Opin Drug Saf 2014;13:227-39.

10. Plottel CS, Blaser MJ. Microbiome and Malignancy. Cell Host Microbe 2011;10:324-35.

11. Marchesi JR, Dutilh BE, Hall N, Peters WHM, Roelofs R, Boleij A, et al. Towards the Human Colorectal Cancer Microbiome. PLOS ONE 2011;6:e20447. doi: 10.1371/journal.pone.00204.

12. Bultman SJ. Emerging roles of the microbiome in cancer. Carcinogenesis 2014;35:249-55.

13. Kumari A, Pasini P, Deo SK, Flomenhoft D, Shashidhar H, Daunert S. Biosensing Systems for the Detection of Bacterial Quorum Signaling Molecules. Anal Chem 2006;78:7603-9. 
14. Macfarlane S, Woodmansey EJ, Macfarlane GT. Colonization of Mucin by Human Intestinal Bacteria and Establishment of Biofilm Communities in a Two-Stage Continuous Culture System. Appl Environ Microbiol 2005;71:7483-92.

15. Casula G, Cutting SM. Bacillus probiotics: Spore germination in the gastrointestinal tract. Appl Environ Microbiol 2002;68:2344-52.

16. De Wever O, Hendrix A, De Boeck A, Westbroek W, Braems G, Emami S, et al. Modeling and quantification of cancer cell invasion through collagen type I matrices. Int J Dev Biol 2010;54:887-96.

17. Sys G, Van Bockstal M, Forsyth R, Balke M, Poffyn B, Uyttendaele D, et al. Tumor grafts derived from sarcoma patients retain tumor morphology, viability, and invasion potential and indicate disease outcomes in the chick chorioallantoic membrane model. Cancer Lett 2012;326:69-78.

18. Ribatti D, Nico B, Vacca A, Presta M. The gelatin-sponge-chorioallantoic membrane assay. Nat Protoc 2006;1:85-91.

19. Wynendaele E, Bronselaer A, Nielandt J, D’Hondt M, Stalmans S, Bracke N, et al. Quorumpeps database: chemical space, microbial origin and functionality of quorum sensing peptides. Nucleic Acids Res 2013;41:D655-9.

20. Verbeke F, Wynendaele E, Braet S, D’Hondt M, De Spiegeleer B. Quality evaluation of synthetic quorum sensing peptides used in R\&D. Journal of Pharmaceutical Analysis 2014, In press.

21. Loboda A, Nebozhyn MV, Watters JW, Buser CA, Shaw PM, Huang PS, et al. EMT is the dominant program in human colon cancer. BMC Med Genomics 2011;4. doi: 10.1186/17558794-4-9. 
22. Perego M, Brannigan JA. Pentapeptide regulation of aspartyl-phosphate phosphatases. Peptides 2001;22:1541-7.

23. Kolodkin-Gal I, Hazan R, Gaathon A, Carmeli S, Engelberg-Kulka HA. Linear Pentapeptide Is a Quorum-Sensing Factor Required for mazEF-Mediated Cell Death in Escherichia coli. Science 2007;318:652-5.

24. Belitsky M, Avshalom H, Erental A, Yelin I, Kumar S, London N, et al. The Escherichia coli Extracellular Death Factor EDF Induces the Endoribonucleolytic Activities of the Toxins MazF and ChpBK. Mol Cell 2011;41:625-35.

25. Willems RJL, van Schaik W. Transition of Enterococcus faecium from commensal organism to nosocomial pathogen. Future Microbiol 2009;4:1125-35.

26. Huycke MM, Joyce W, Wack MF. Augmented Production of Extracellular Superoxide by Blood Isolates of Enterococcus faecalis. J Infect Dis 1996;173:743-6.

27. Buchanan FG, Gorden DL, Matta P, Shi Q, Matrisian LM, DuBois RN. Role of $\beta$-arrestin 1 in the metastatic progression of colorectal cancer. Proc Natl Acad Sci USA 2006;103:14927.

28. Roberts AB, Tian F, DaCosta Byfield S, Stuelten C, Ooshima A, Saika S, et al. Smad3 is key to TGF- $\beta$-mediated epithelial-to-mesenchymal transition, fibrosis, tumor suppression and metastasis. Cytokine Growth Factor Rev 2006;17:19-27.

29. Wildi S, Kleeff J, Maruyama H, Maurer CA, Büchler MW, Korc M. Overexpression of activin A in stage IV colorectal cancer. Gut 2001;49:409-17.

30. Wang Z, Li Y, Kong D, Sarkar FH. The role of Notch Signaling Pathway in EpithelialMesenchymal Transition (EMT) During Development and Tumor Aggressiveness. Curr Drug Targets 2010;11:745-51. 
31. Bunnell TM, Burbach BJ, Shimizu Y, Ervasti JM. $\beta$-actin specifically controls cell growth, migration, and the G-actin pool. Mol Biol Cell 2011;22:4047-58.

32. Su JL, Chen PB, Chen YH, Chen SC, Chang YW, Jan YH, et al. Downregulation of microRNA miR-520h by E1A Contributes to Anti-cancer Activity. Cancer Res 2010;70:5096-108.

33. Galon J, Mlecnik B, Pages F, Fridman H. Method for predicting the outcome of colon cancer by analyzing mirna expression. 2013, US Patent application number: 20130331291.

34. Sikand K, Singh J, Ebron JS, Shukla GC. Housekeeping Gene Selection Advisory: Glyceraldehyde-3-Phosphate Dehydrogenase (GAPDH) and $\beta$-Actin Are Targets of miR644a. PLOS ONE 2012;7. doi: 10.1371/journal.pone.0047510.

35. Yu L, Zhang L, Hwang PM, Kinzler KW, Vogelstein B. PUMA Induces the Rapid Apoptosis of Colorectal Cancer Cells. Mol Cell 2001;7:673-82.

36. Le X, Merchant O, Bast Jr RC, Calin GA. The Roles of MicroRNAs in the Cancer InvasionMetastasis Cascade. Cancer Microenviron 2010;3:137-47.

37. Neufeld G, Kessler O. Pro-angiogenic cytokines and their role in tumor angiogenesis. Cancer Metastasis Rev 2006;25:373-85.

38. Fisher DT, Appenheimer MM, Evans SS. The two faces of IL-6 in the tumor microenvironment. Semin Immunol 2014;26:38-47.

39. Seruga B, Zhang H, Bernstein LJ, Tannock IF. Cytokines and their relationship to the symptoms and outcome of cancer. Nat Rev Cancer 2008;8:887-99.

40. Spano J-P, Lagorce C, Atlan D, Milano G, Domont J, Benamouzig R, et al. Impact of EGFR expression on colorectal cancer patient prognosis and survival. Ann Oncol 2005;16:102-8. 
41. De Luca A, Carotenuto A, Rachiglio A, Gallo M, Maiello MR, Aldinucci D, et al. The role of the EGFR signaling in tumor microenvironment. J Cell Physiol 2007;214:559-67.

42. Fischer OM, Hart S, Gschwind A, Ullrich A. EFGR signal transactivation in cancer cells. Biochem Soc Trans 2003;31:1203-8.

43. Meulmeester E, ten Dijke P. The dynamic roles of TGF- $\beta$ in cancer. J Pathol 2011;223:20518.

44. Hu Y, Zheng M, Zhang R, Liang Y, Han H. Notch signaling pathway and cancer metastasis. In: Reichrath J, Reichrath S, editors. Notch signaling in embryology and cancer, Austin: Landes Bioscience; 2011, p. 186-198.

45. Wang S, Liu Z, Wang L, Zhang X. NF-kappaB signaling pathway, inflammation and colorectal cancer. Cell Mol Immunol 2009;6:327-34.

46. Fabian MR, Sonenberg N. The mechanics of miRNA-mediated gene silencing: a look under the hood of miRISC. Nat Struct Mol Biol 2012;19:586-93.

47. Nicoloso MS, Spizzo R, Shimizu M, Rossi S, Calin GA. MicroRNAs - the micro steering wheel of tumour metastases. Nat Rev Cancer 2009;9:293-302.

48. Ho YP, Kuo CW, Hsu YT, Huang YS, Yew LP, Huang WF, et al. $\beta$-Actin is a downstream effector of the PI3K/AKT signaling pathway in myeloma cells. Mol Cell Biochem 2011;348:129-39.

49. Wei L, Kuo ML, Chen CA, Chou CH, Lai KB, Lee $\mathrm{CN}$, et al. Interleukin-6 promotes cervical tumor growth by VEGF-dependent angiogenesis via a STAT3 pathway. Oncogene 2003;22:1517-27.

50. Teicher BA, Fricker SP. CXCL12 (SDF-1)/CXCR4 pathway in cancer. Clin Cancer Res 2010;16:2927-31. 
51. Cecchi F, Rabe DC, Bottaro DP. Targeting the HGF/Met signaling pathway in cancer therapy. Expert Opin Ther Targets 2012;16:553-72.

52. Turnbaugh PJ, Ridaura VK, Faith JJ, Rey FE, Knight R, Gordon JI. The Effect of Diet on the Human Gut Microbiome: A Metagenomic Analysis in Humanized Gnotobiotic Mice. Sci Transl Med 2009;1. doi: 10.1126/scitranslmed.3000322.

53. Zarrinpar A, Chaix A, Yooseph S, Panda S. Diet and feeding pattern affect the diurnal dynamics of the gut microbiome. Cell metab 2014;20:1006-17. 


\section{FIGURES}

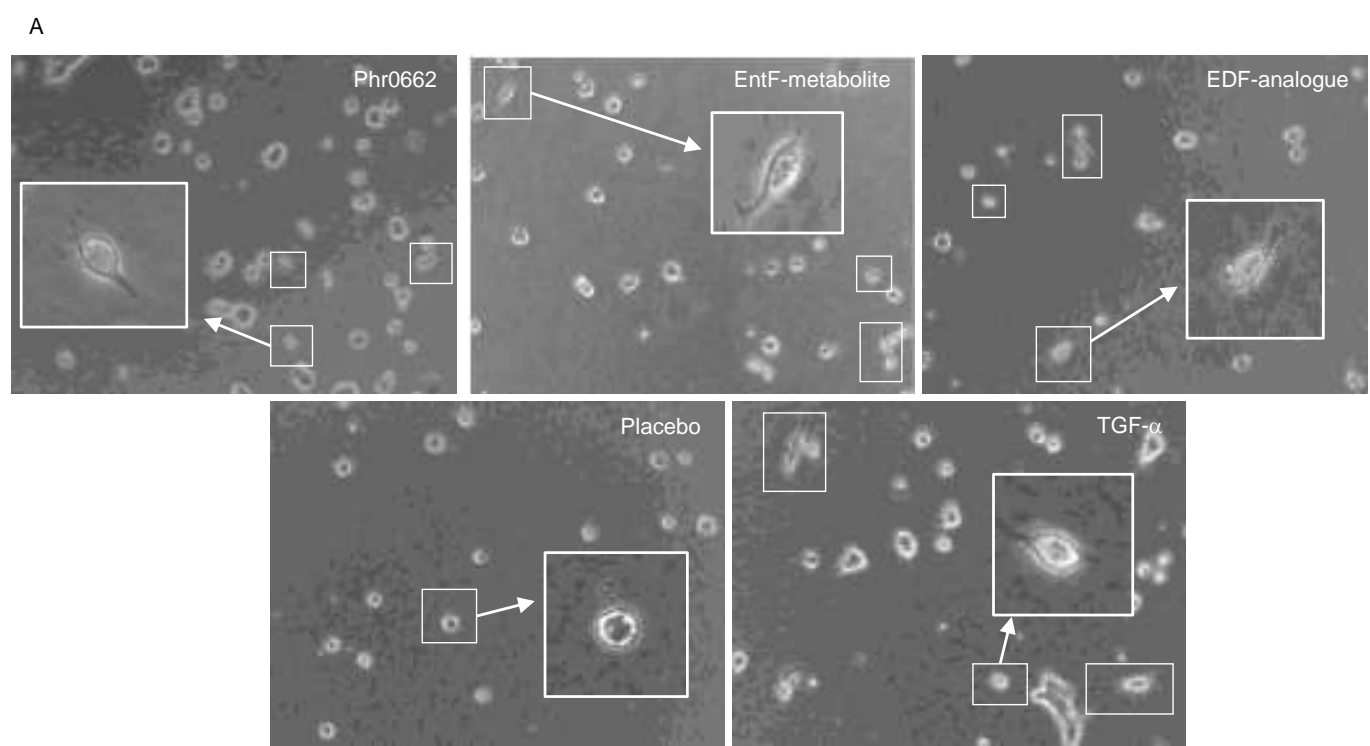

B

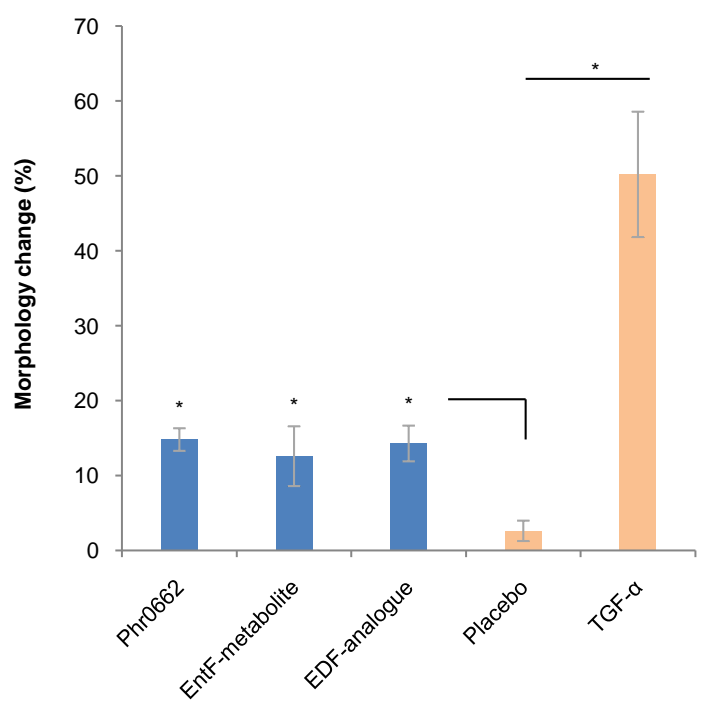

Figure 1: Collagen invasion of 3 quorum sensing peptides at $10 \mathrm{nM}$. (A) Morphologic changes of HCT-8/E11 cells, observed 24 hours post-treatment with Phr0662 (ERNNT), EntF-metabolite (SNLVECVFSLFKKCN) and EDF-analogue (NWN). Placebo sample serves as negative control and TGF- $\alpha(0.1 \mu \mathrm{g} / \mathrm{ml})$ as the very strong positive control. Samples were additionally tested at $100 \mathrm{nM}$ and $1 \mu \mathrm{M}$, showing invasion at these concentrations as well (data not depicted). (B) Mean $(\mathrm{n}=3)$ percentage of cancer cells with induced morphology changes: a significant difference is observed between the peptide and placebo treatments (* $\mathrm{p}<0.05$ (Mann-Whitney U test)). Error bars represent SEM values. 

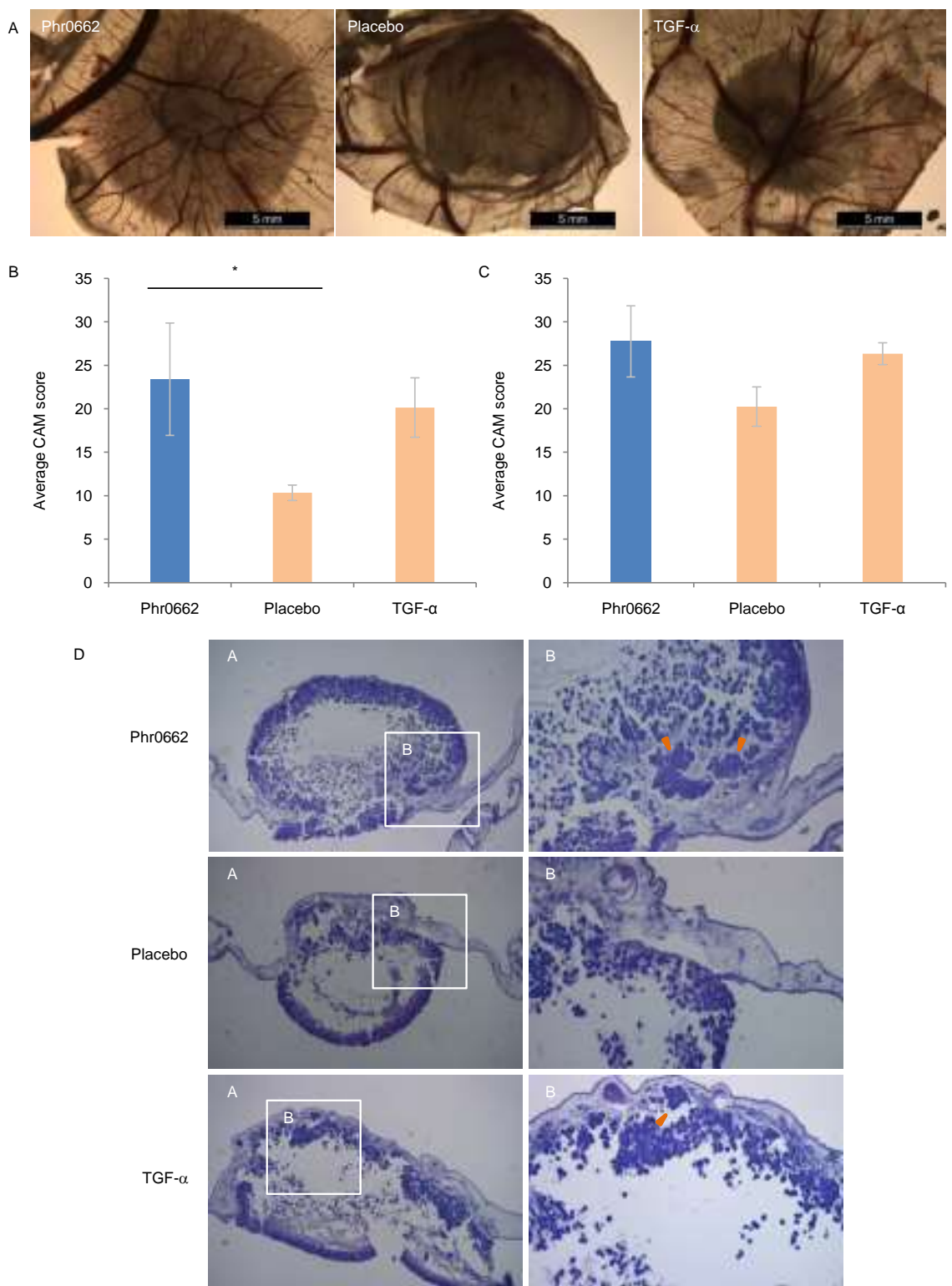

Figure 2: Neovascularisation and cell invasion after Phr0662 (100 nM) addition to HCT-8/E11 cells on CAM.

Placebo sample serves as negative control and TGF- $\alpha(0.1 \mu \mathrm{g} / \mathrm{ml})$ as positive control. (A) Macroscopic images, observed 6 days after (pre-treated) tumor cell transfer to the eggs. (B) Average CAM Score (i.e. number of blood vessels in the $1 \mathrm{~mm}$ diameter ring around the $2 \mathrm{~mm}$ radius centre) in the presence of tumor cells (mean $\pm \mathrm{SEM}, \mathrm{n}=5$ (Phr0662), $\mathrm{n}=7$ (TGF- $\alpha$ ) or $\mathrm{n}=3$ (placebo)). (C) Average CAM Score when no tumor cells are present (mean \pm SEM, $n=8($ Phr0662 and placebo) or $n=6($ TGF- $\alpha)$ ). (D) Histological H\&E evaluation of the CAM, with orange arrowheads indicating invasion of the tumor cells into the mesoderm.

$* \mathrm{p}<0.05$ (Mann-Whitney U test) 


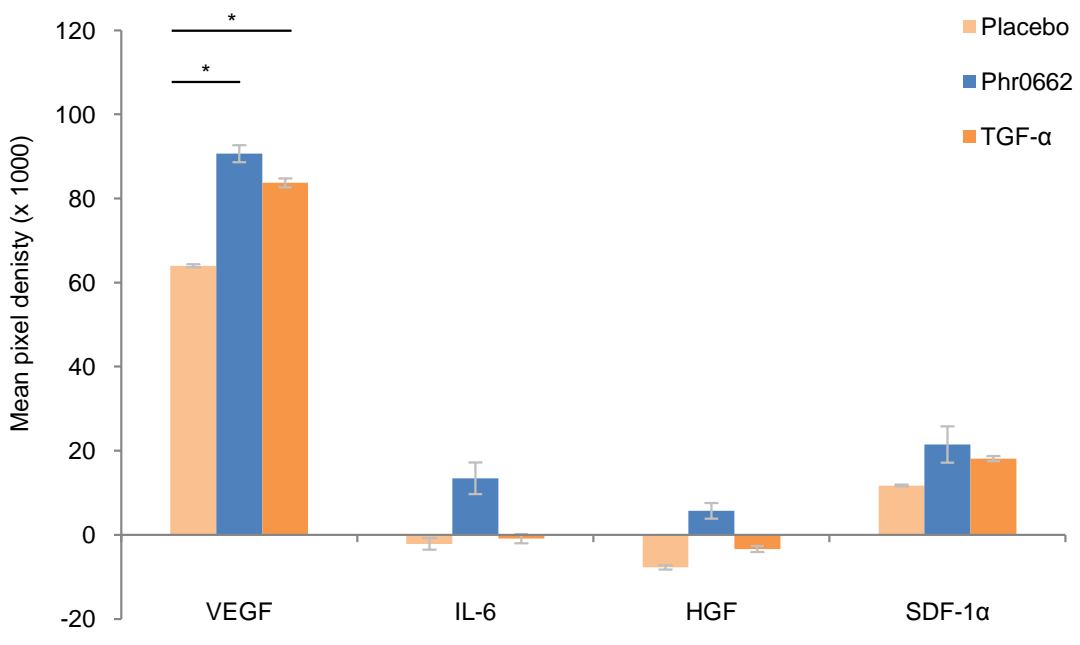

B

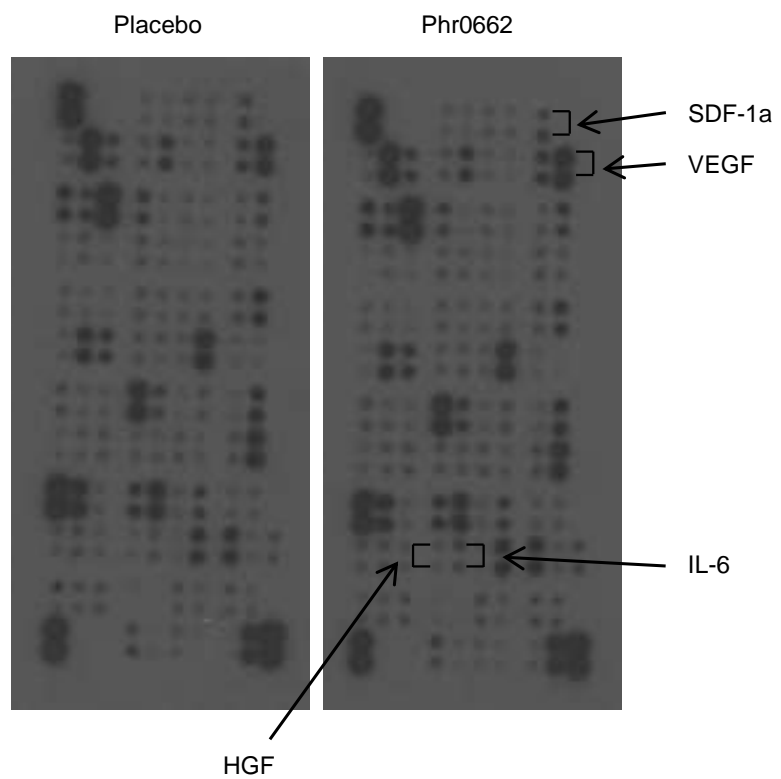

Figure 3: Effect of quorum sensing peptide Phr0662 (100 nM) on cytokine expression in HCT-8/E11 colon cancer cells. Placebo sample serves as the negative control and TGF- $\alpha(0.1 \mu \mathrm{g} / \mathrm{ml})$ as the positive control. (A) Mean $(\mathrm{n}=2, \pm \mathrm{SEM})$ pixel density of some pro-angiogenic cytokines, demonstrating increasing cytokine concentrations after Phr0662 addition (24 hours of peptide incubation); * p $<0.05$ (independent samples t-test). (B) Human XL Cytokine Array visually demonstrating increased cytokine levels after peptide treatment of HCT-8/E11 cells, compared to placebo samples. The selected pro-angiogenic cytokines (in duplo) are indicated. 
A

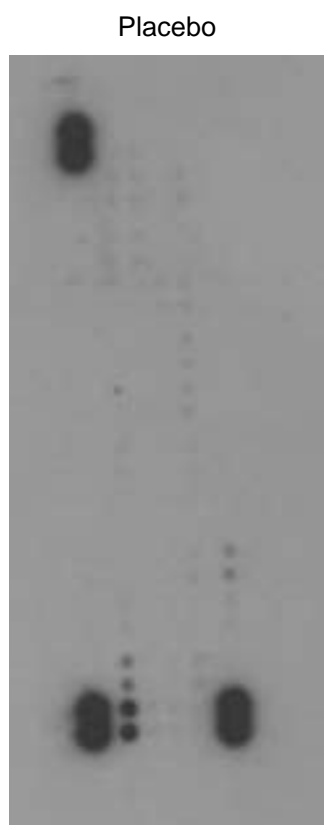

Phr0662

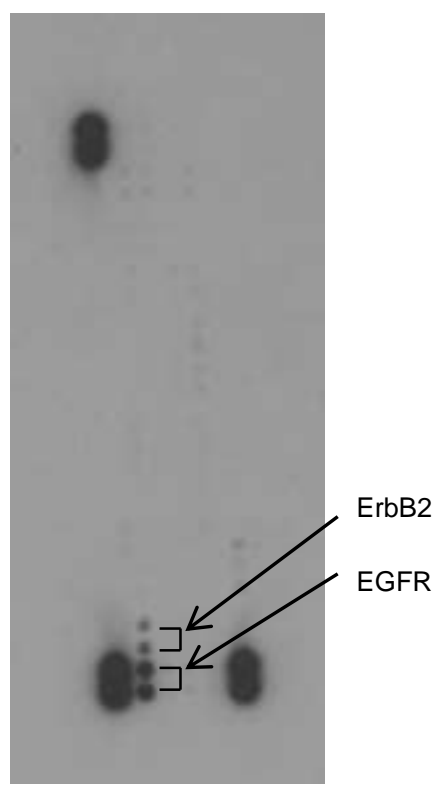

B

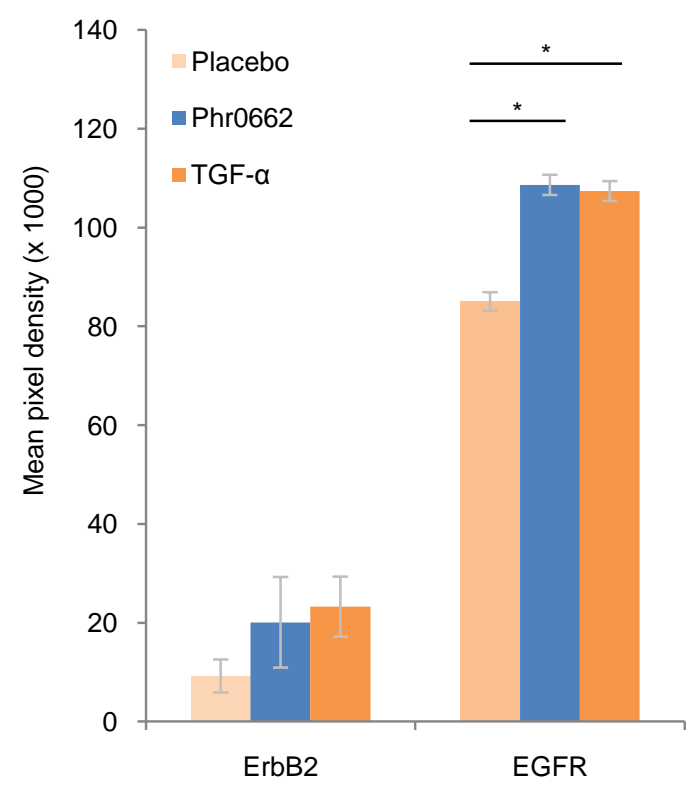

Figure 4: Effect of quorum sensing peptide Phr0662 (100 $\mathrm{nM})$ on receptor tyrosine kinase activation in colon cancer cells. Placebo sample serves as the negative control and TGF- $\alpha(0.1 \mu \mathrm{g} / \mathrm{ml})$ as the positive control. (A) Receptor tyrosine kinase (RTK) array demonstrating the tyrosine phosphorylation level of 42 RTK after Phr0662 treatment of HCT-8/E11. Each RTK is spotted in duplicate and the phosphorylated EGFR and ErbB2 are indicated. (B) Mean (n = 2, \pm SEM) pixel density of ErbB2 and EGFR spots after Phr0662 addition (5 minutes of peptide incubation); ${ }^{*} \mathrm{p}<0.05$ (independent samples t-test). TGF- $\alpha$ serves as the cognate ligand for EGFR, demonstrating thus EGFR binding properties for the quorum sensing peptide. 


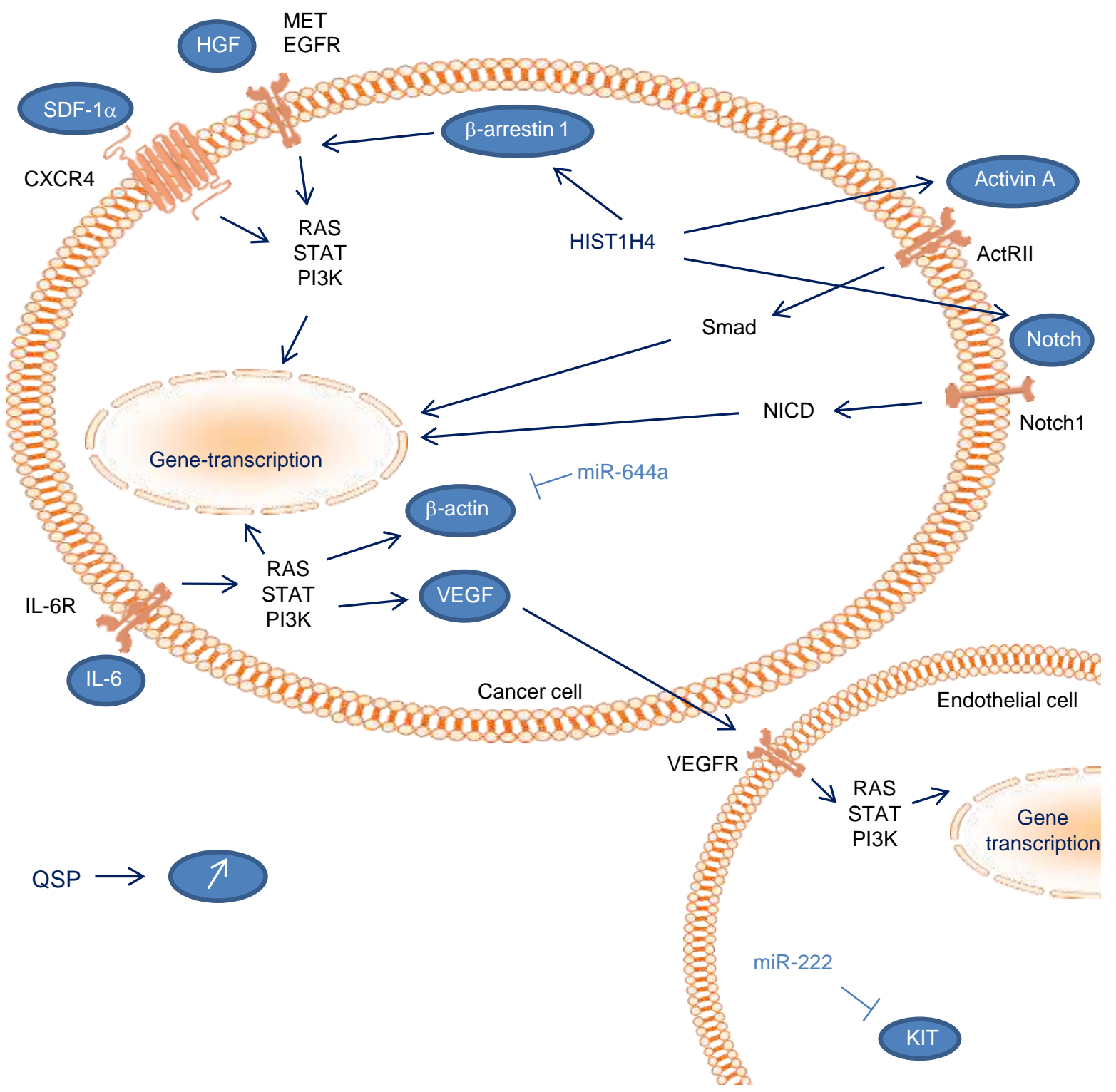

Figure 5: Possible pathway-map for quorum sensing peptides in tumor progression. Quorum sensing peptides promote cancer metastasis and tumor progression by activating different receptor pathways. 


\section{TABLES}

\section{Table 1: Selection of transcriptome alterations after quorum sensing peptide addition to}

HCT-8/E11 cells. Gene expression 24 hours post-treatment, compared to placebo samples.

Mean fold change is calculated from duplicate samples (cut off: $>1.5$ or $<-1.5$ ).

\begin{tabular}{|c|c|c|c|c|}
\hline \multicolumn{5}{|c|}{ Phr0662 } \\
\hline \multicolumn{2}{|c|}{ Gene symbol } & \begin{tabular}{|l|} 
Fold change \\
\end{tabular} & ANOVA p-value & Description \\
\hline $\begin{array}{l}\text { UP- } \\
\text { REGULATED }\end{array}$ & $\begin{array}{c}\text { SCARNA10 } \\
\text { RN5S348 } \\
\text { MIR } 4521 \\
\text { HIST1H4A-F/H-L } \\
\text { CXOrf61 } \\
\text { SNORA26 } \\
\end{array}$ & $\begin{array}{l}1.99 \\
1.69 \\
1.60 \\
2.02 \\
1.54 \\
1.63 \\
\end{array}$ & $\begin{array}{l}0.024 \\
0.272 \\
0.335 \\
0.647 \\
0.054 \\
0.095\end{array}$ & $\begin{array}{l}\text { Small Cajal body-specific RNA } 10 \\
\text { RNA, 5S ribosomal } 348 \\
\text { MicroRNA } 4521 \\
\text { Histone cluster } 1, \mathrm{H} 4 \mathrm{~d}, \ldots \\
\text { Chromosome X open reading frame } 61 \\
\text { Small nucleolar RNA, H/ACA box } 26 \\
\end{array}$ \\
\hline $\begin{array}{l}\text { DOWN- } \\
\text { REGULATED }\end{array}$ & $\begin{array}{l}\text { RPL36AP33 } \\
\text { RNU6-51 } \\
\text { MIR } 222 \\
\text { SNORD121B } \\
\text { SNORD85 } \\
\text { ARL17A } \\
\text { RNU7-47P } \\
\end{array}$ & $\begin{array}{l}-1.75 \\
-1.99 \\
-1.60 \\
-1.88 \\
-1.84 \\
-1.74 \\
-1.72 \\
\end{array}$ & $\begin{array}{l}0.576 \\
0.565 \\
0.593 \\
0.242 \\
0.323 \\
0.543 \\
0.463 \\
\end{array}$ & $\begin{array}{l}\text { Ribosomal protein L36a pseudogene } 33 \\
\text { RNA, U6 small nuclear } 51 \\
\text { MicroRNA } 222 \\
\text { Small nucleolar RNA, C/D box 121B } \\
\text { Small nucleolar RNA, C/D box } 85 \\
\text { ADP-ribosylation factor-like 17A } \\
\text { RNA, U7 small nuclear } 47 \text { pseudogene }\end{array}$ \\
\hline \multicolumn{5}{|c|}{ EntF-metabolite } \\
\hline \multicolumn{2}{|c|}{ Gene symbol } & \begin{tabular}{|l|} 
Fold change \\
\end{tabular} & ANOVA p-value & Description \\
\hline $\begin{array}{l}\text { UP- } \\
\text { REGULATED }\end{array}$ & $\begin{array}{l}\text { RN5S62 } \\
\text { OR52E6 }\end{array}$ & $\begin{array}{l}1.79 \\
1.58\end{array}$ & $\begin{array}{l}0.534 \\
0.479\end{array}$ & $\begin{array}{l}\text { RNA, } 5 \text { S ribosomal } 62 \\
\text { Olfactory receptor, family 52, subfamily } \\
\text { E, member } 6 \\
\end{array}$ \\
\hline $\begin{array}{l}\text { DOWN- } \\
\text { REGULATED }\end{array}$ & $\begin{array}{l}\text { RNU7-47P } \\
\text { MIR597 } \\
\text { MIR548T } \\
\text { RNY4 } \\
\text { MIR558 } \\
\text { LOC } 286437 \\
\text { RNY4P2 } \\
\text { MIR644A } \\
\text { MIR3975 } \\
\text { MIR553 }\end{array}$ & $\begin{array}{l}-1.83 \\
-1.65 \\
-1.58 \\
-1.56 \\
-1.68 \\
-1.64 \\
-1.61 \\
-1.98 \\
-1.63 \\
-1.95\end{array}$ & $\begin{array}{l}0.340 \\
0.599 \\
0.597 \\
0.007 \\
0.090 \\
0.390 \\
0.231 \\
0.443 \\
0.088 \\
0.328 \\
\end{array}$ & $\begin{array}{l}\text { RNA, U7 small nuclear } 47 \text { pseudogene } \\
\text { MicroRNA } 597 \\
\text { MicroRNA 548t } \\
\text { RNA, Ro-associated Y4 } \\
\text { MicroRNA 558 } \\
\text { Uncharacterized LOC286437 } \\
\text { RNA, Ro-associated Y4 pseudogene } 2 \\
\text { MicroRNA 644a } \\
\text { MicroRNA 3975 } \\
\text { MicroRNA 553 }\end{array}$ \\
\hline \multicolumn{5}{|c|}{ EDF-analogue } \\
\hline \multicolumn{2}{|c|}{ Gene symbol } & \begin{tabular}{|l|} 
Fold change \\
\end{tabular} & ANOVA p-value & Description \\
\hline $\begin{array}{c}\text { UP- } \\
\text { REGULATED }\end{array}$ & OR52E6 & 1.70 & 0.384 & $\begin{array}{l}\text { Olfactory receptor, family 52, subfamily } \\
\text { E, member } 6\end{array}$ \\
\hline $\begin{array}{c}\text { DOWN- } \\
\text { REGULATED }\end{array}$ & $\begin{array}{c}\text { MIR222 } \\
\text { RNU7-19P }\end{array}$ & $\begin{array}{r}-1.51 \\
-1.68\end{array}$ & $\begin{array}{l}0.641 \\
0.008\end{array}$ & $\begin{array}{l}\text { MicroRNA } 222 \\
\text { RNA, U7 small nuclear } 19 \text { pseudogene }\end{array}$ \\
\hline
\end{tabular}


Table S1. Peptide information

\begin{tabular}{|c|c|}
\hline $\begin{array}{c}\text { Quorumpeps } \\
\text { ID }\end{array}$ & Sequence \\
\hline 2 & FNTIPSY \\
\hline 5 & Ac-CGSLF, thiolacton linkage between C1 and F5 \\
\hline 7 & FNTWPSY \\
\hline 10 & ADLPFEF \\
\hline 11 & AGTKPQGKPASNLVECVFSLFKKCN \\
\hline 13 & AIFILAS \\
\hline 14 & AITLIFI \\
\hline 15 & AKDEH \\
\hline 16 & AKTVQ \\
\hline 17 & ALILTLVS \\
\hline 18 & ARNQT \\
\hline 19 & NNWNN \\
\hline 22 & CVGIW, thiolacton linkage between $\mathrm{C} 1$ and W5 \\
\hline 24 & CTFTLPGGGGVCTLTSECIC \\
\hline 25 & CVFSLFKKCN \\
\hline 28 & DIRHRINNSIWRDIFLKRK \\
\hline 30 & DLRGVPNPWGWIFGR \\
\hline 31 & DLRNIFLKIKFKKK \\
\hline 32 & DMCNGYF, thiolacton linkage between $\mathrm{C} 3$ and F7 \\
\hline 34 & DRVGA \\
\hline 40 & DSVCASYF, thiolacton linkage between C4 and F8 \\
\hline 42 & DWRFLNSIRDLIFPKRK \\
\hline 44 & EKMIG \\
\hline 45 & EMRISRIILDFLFLRKK \\
\hline 46 & EMRKSNNNFFHFLRRI \\
\hline 47 & EMRLPKILRDFIFPRKK \\
\hline 49 & EQLSFTSIGILQLLTIGTRSCWFFYCRY \\
\hline 50 & ERGMT \\
\hline 51 & ERNNT \\
\hline 52 & ERPVG \\
\hline 53 & ESRLPKILLDFLFLRKK \\
\hline 54 & ESRLPKIRFDFIFPRKK \\
\hline 55 & ESRVSRIILDFLFQRKK \\
\hline 56 & VNYGNGVSCSKTKCSVNWGQAFQERYTAGINSFVSGVASGAGSIGRRP \\
\hline 58 & DSRIRMGFDFSKLFGK \\
\hline 62 & ESRISDILLDFLFQRKK \\
\hline 71 & QNCPNIFGQWM, lacton linkage between S3 and M11 \\
\hline 75 & SINSQIGKATSNLVECVFSLFKKCN \\
\hline 76 & SNLVECVFSLFKKCN \\
\hline 81 & FNTIPKY \\
\hline 82 & NTIPKY \\
\hline
\end{tabular}


Table S1. Peptide information (continued)

\begin{tabular}{|c|c|}
\hline $\begin{array}{c}\text { Quorumpeps } \\
\text { ID }\end{array}$ & Sequence \\
\hline 84 & FFNTCPSY \\
\hline 85 & FNTCPSY \\
\hline 92 & FHWWQTSPAHFS \\
\hline 93 & FLVMFLSG \\
\hline 97 & QNSPNIFGQWM, lacton linkage between S3 and M11 \\
\hline 99 & GKAEF \\
\hline 100 & GKATSSISKCVFSFFKKC \\
\hline 101 & GLWEDILYSLNIIKHNNTKGLHHPIQL \\
\hline 102 & GLWEDLLYNINRYAHYIT \\
\hline 103 & GNWNN \\
\hline 105 & GSQKGVYASQRSFVPSWFRKIFRN \\
\hline 107 & GVNACSSLF, thiolacton linkage between C5 and F9 \\
\hline 111 & GWWEDFLYRFNIIEQKNTKGFYQPIQL \\
\hline 121 & ILSGAPCIPW \\
\hline 123 & IRFVT \\
\hline 125 & KSSAYSLQMGATAIKQVKKLFKKWGW \\
\hline 132 & LFSLVLAG \\
\hline 133 & LFVVTLVG \\
\hline 134 & LPFEF \\
\hline 135 & LPFEH \\
\hline 137 & LVTLVFV \\
\hline 138 & MAGNSSNFIHKIKQIFTHR \\
\hline 140 & MKAEH \\
\hline 143 & MPFEF \\
\hline 146 & NEVPFEF \\
\hline 147 & NGWNN \\
\hline 148 & YSTCDFIM, thiolacton linkage between C4 and M8 \\
\hline 151 & NNGNN \\
\hline 152 & NNNWNNN \\
\hline 153 & NNWGN \\
\hline 154 & NNWNG \\
\hline 155 & NWN \\
\hline 156 & FNTIP \\
\hline 157 & FNTWP \\
\hline 160 & QKGMY \\
\hline 162 & QRGMI \\
\hline 164 & SDLPFEH \\
\hline 165 & SDMPFEF \\
\hline 166 & SGSLSTFFLLFNRSFTQALGK \\
\hline 174 & SGSLSTFFRLFNRSFTQALG \\
\hline 176 & SGSLSTFFRLFNRSFTQALGK \\
\hline
\end{tabular}


Table S1. Peptide information (continued)

\begin{tabular}{|c|l|}
\hline $\begin{array}{c}\text { Quorumpeps } \\
\text { ID }\end{array}$ & \multicolumn{1}{|c|}{ Sequence } \\
\hline 177 & SGSLSTFFRLFNRSFTQALGKIR \\
180 & SGSLSTFFRLFNRSQTQALGK \\
184 & SIFTLVA \\
186 & SKDYN \\
188 & SLSTFFRLFNFSFTQALG \\
191 & SRKAT \\
192 & SRNAT \\
193 & SRNVT \\
206 & SYPGWSW \\
207 & TAGPAIRASVKQCQKTLKATRLFTVSCKGKNGCK \\
208 & TNRNYGKPNKDIGTCIWSGFRHC \\
210 & VAVLVLGA \\
212 & VPFEF \\
214 & WPFAHWPWQYPR \\
215 & FNTWPKY \\
218 & YNPCSNYL, thiolacton linkage between C4 and L8 \\
\hline
\end{tabular}

